\title{
KARAKTERISTIK KABEL YANG DI TEKUK SAAT DI ALIRI ARUS
}

\author{
Emidiana, Matra Widodo \\ Program Studi Teknik Elektro Fakultas Teknik Universitas PGRI Palembang \\ e-mail : emidiana@univpgri-palembang.ac.id
}

\begin{abstract}
ABSTRAK Pada pemasangan kabel instalasi listrik, baik instalasi untuk perumahan, perkantoran maupun industry, kabelnya kadang-kadang harus ditekuk. Penekukan kabel ini akan mempengaruhi karakteristik kabel, salah satunya merubah nilai tahanan kabel. Penelitian ini akan membahas mengenai pengaruh tekukan kabel terhadap nilai tahanan. Data diambil dengan melakukan eksperimen dengan mengalirkan tegangan dan arus pada kabel yang tanpa di ditekuk dan dengan kabel yang ditekuk dengan satu kali, dua kali, tiga kali, empat kali dan lima kali tekukan. Dari hasil pengujian tersebut dilakukan perhitungan dan didapat hasil sebagai berikut : untuk kabel yang tidak ditekuk, nilai tahanannya adalah $900 \mathrm{Ohm} / \mathrm{km}$. Kabel yang ditekuk satu kali, nilai tahanannya adalah $600 \mathrm{Ohm} / \mathrm{km}$. Sedangkan untuk kabel yang ditekuk dua kali tahanannya $700 \mathrm{Ohm} / \mathrm{km}$, ditekuk tiga kali tahannanya menjadi $550 \mathrm{Ohm} / \mathrm{km}$, empat kali 700 $\mathrm{Ohm} / \mathrm{km}$ dan lima kali $560 \mathrm{Ohm} / \mathrm{km}$. Hasil pengukuran yang naik turun tersebut terjadi karena arah tekukan yang tidak selalu searah.
\end{abstract}

Kata Kunci : kabel NYM, tekukan, Ohm/km

ABSTRACT In the installation of electrical wiring, both installations for housing, offices and industry, the cables sometimes have to be bent. This cable bending will affect cable characteristics, one of which changes the cable resistance value. This study will discuss the effect of cable bending on the value of resistance. Data is taken by experimenting with a voltage and current flowing on a cable that is not bent and with a cable that is bent once, twice, thrice, four times and five times bending. From the results of the test, the calculation is obtained and the following results are obtained: for cables that are not bent, the resistance value is $900 \mathrm{Ohm}$ $/ \mathrm{km}$. The cable is bent once, the resistance value is $600 \mathrm{Ohm} / \mathrm{km}$. Whereas for cables that are bent twice at $700 \mathrm{Ohm} / \mathrm{km}$, they are bent three times to $550 \mathrm{Ohm} / \mathrm{km}$, four times $700 \mathrm{Ohm} /$ $\mathrm{km}$ and five times $560 \mathrm{Ohm} / \mathrm{km}$. The up and down measurement results occur because the bending direction is not always in the same direction.

Keywords: NYM cable, bending, Ohm / km

\section{PENDAHULUAN}

Sebagai salah satu komponen yang sangat penting dalam penyaluran daya listrik, kabel perlu mendapat perhatian yang serius. Salah satu masalah yang mungkin terjadi adalah penekukan kabel pada saat kabel tersebut diinstalasi. Dalam pemasangannya, kabel tidak selalu dipasang lurus, kadang - kadang harus ditekuk. Hal ini akan mempengaruhi karakteristik kabel tersebut, salah satunya nilai resistansinya. Berubahnya nilai resistansi pada kabel tersebut, menyebabkan naiknya rugi daya pada kabel tersebut, yang menyebabkan kabel menjadi panas.

Dalam penelitian ini permasalahan yang dikaji adalah:

1. Bagaimana perubahan tahanan konduktor dari kabel NYM saat ditekuk.

2. Bagaimana cara menghitung perubahan tahanan kebel NYM saat ditekuk

3. Bagaimana menganalisa perubahan besar kecilnya nilai tahanan kabel NYM saat ditekuk 
Untuk menjaga agar permasalahan dalam penelitian ini tidak meluas, maka di batasi hanya pada:

1. kabel yang diuji adalah kabel NYM dengan 2 penghantar berinti tunggal dengan luas penampang konduktor $1.5 \mathrm{~mm} 2$ jenis NYM 300/500 Volt.

2. Pengujian dilakukan dengan tegangan bolak-balik (AC) variabel $0-220$ Volt.

3. Penekukan kabel di lakukan dengan lima kali penekukan.

Adapun tujuan dari penelitian ini adalah :

1. Meghitung tahanan konduktor dari kabel NYM yang di tekuk saat di aliri arus.

2. Menghitung rugi daya pada kabel yang diuji

3. Menganalisa perubahan nilai tahanan kabel NYM saat di tekuk sampai beberapa kali.

\section{TINJAUAN PUSTAKA}

Penghantar listrik terdiri dari dua macam yaitu kabel dan kawat. Kawat merupakan penghantar tanpa isolasi (telanjang) yang terbuat dari tembaga $(\mathrm{Cu})$ dan / atau aluminium $(\mathrm{Al})$, sedangkan kabel adalah penghantar yang dibungkus bahan isolasi, baik yang berinti tunggal maupun banyak. Jenisnya ada yang kaku ada juga yang berserabut. Sedangkan berdasarkan pemasangannya terbagi atas kabel udara dan kabel tanah. [3]

Salah satu permasalahan yang sering terjadi pada kabel adalah kegagalan isolasi, sehingga bahan isolasi tidak dapat melakukan fungsinya dengan baik. Salah satu penyebabnya adalah karena panas yang terjadi pada kabel yang merusak isolasi kabel tersebut.[2] Pemasangan kabel yang ditekuk menjadi salah satu penyebab panasnya kabel tersebut.

Kabel yang digunakan untuk instalasi rumah adalah kabel kawat tembaga. Kabel kawat tembaga yang umum dipakai adalah tipe kabel NYA, NYM dan NYY.[6]

\section{Kabel NYA[4]}

Kabel NYA berinti tunggal, dengan lapisan isolasi dari bahan PVC, digunakan untuk instalasi luar atau kabel udara. Kode warna isolasinya antara lain warna merah, kuning, biru dan hitam berdasarkan peraturan PUIL. Lapisan isolasinya hanya 1 lapis yang menyebabkan kabel tersebut mudah rusak, tidak tahan air (NYA adalah tipe kabel udara) dan mudah digigit tikus. Untuk menjaga keamanan ketika kita memakai kabel ini, kabel harus dipasang dalam pipa/conduit jenis PVC atau saluran tertutup agar tidak digigit tikus dan bila isolasinya terkelupas tidak tersentuh langsung. 


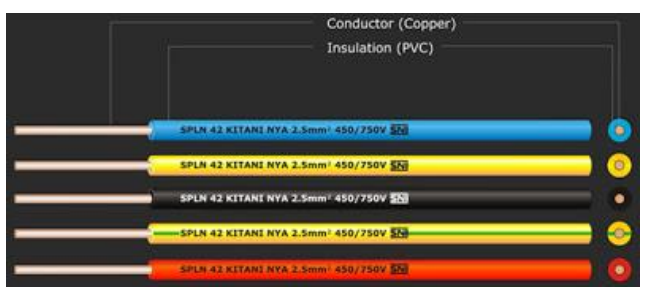

Gambar 1. Kabel NYA[5]

\section{Kabel NYM[1]}

Kabel ini memiliki isolasi PVC yang berwarna putih atau abu-abu. Kabel NYM memiliki isolasi 2 lapis sehingga relatif lebih aman dari pada kabel NYA dan harganya juga lebih mahal. Kabel NYA dapat digunakan baik di lingkungan yang kering dan basah tetapi tidak boleh ditanam.

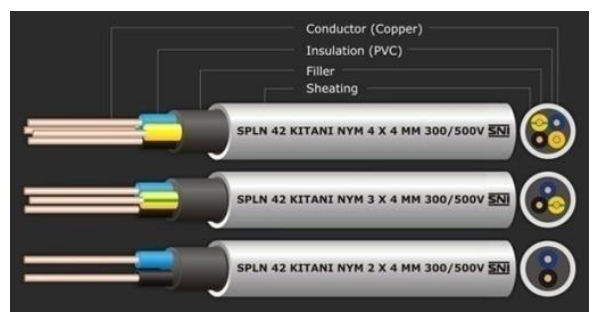

Gambar 2. Kabel NYM[5]

\section{Kabel NYY[4]}

Kabel NYY dengan lapisan isolasi dari bahan PVC (biasanya berwarna hitam), jumlah intinya 2, 3 atau 4. Kabel NYY digunakan pada instalasi yang ditanam (kabel tanah), dan mempunyai lapisan isolasi yang lebih kuat serta terbuat dari bahan yang tidak disukai tikus. Jika dibandingkan dengan kabel NYM, harganya lebih mahal.

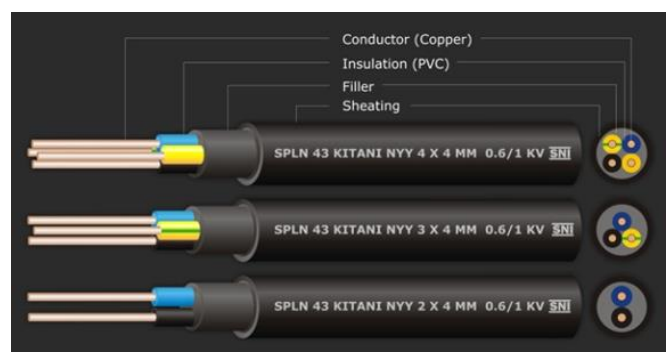

Gambar 3. Kabel NYY[5]

\section{METODE PENELITIAN}

Penelitian dilakukan di laboratorium Universitas PGRI Palembang, yang beralamat di Jl. Jend A. Yani Lorong Gotong Royong No. 9/10 13 Ulu, Seberang Ulu II, Kota Palembang, Sumatera Selatan. Objek yang digunakan untuk pengujian adalah kabel NYM 2x $1.5 \mathrm{~mm}^{2}$ dengan standar SPLN-42. 
Adapun parameter teknis dari kabel yang menggunakan standar SPLN-42 adalah sebagai berikut:

Jumlah inti dan luas penampang : $2 \times 1.5 \mathrm{~mm}^{2}$

Jumlah kawat dalam satu inti : 1 buah

Diameter inti kabel

: $1.38 \mathrm{~mm}$

Isolasi nominal S1

: $0.7 \mathrm{~mm}$

Lapisan pembungkus inti S2

: $0.4 \mathrm{~mm}$

Selubung nominal S3

$: 1.2 \mathrm{~mm}$

Diameter luar

: $10 \mathrm{~mm}$

\section{Langkah penelitian}

Langkah penelitian dilakukan dengan cara mengalirkan sumber tegangan AC 220V ke kabel listrik dan di uraikan sebagai berikut :

1. Menyiapkan semua peralatan

2. Menyiapkan kabel yang akan diuji

3. Merangkai rangkaian penelitian

4. Mengalirkan sumber tegangan ke kabel

5. Mencatat data hasil pengukuran

6. Menghitung perubahan nilai tahanan jenis penghantar dari pengujian

7. Menganalisa perubahan nilai tahanan jenis penghantar dari pengujian

\section{Metode perhitungan}

\section{Menghitung tahanan konduktor}

$$
\mathrm{Rac}=\frac{V a c}{\mathrm{Iac}}
$$

Keterangan :

Rac : tahanan kawat $(\Omega / \mathrm{ohm})$

Vac : tegangan (Volt)

Iac $\quad$ arus listrik (Ampere)

\section{Menghitung rugi daya}

$$
\Delta \mathbf{P} \quad=\mathbf{I}^{2} \cdot \mathbf{R}
$$

Keterangan :

$\Delta \mathrm{P}=$ rugi daya $($ watt $)$

$\mathrm{I}=$ arus (ampere)

$\mathrm{R}=$ tahanan (ohm) 


\section{HASIL DAN ANALISA}

\section{Data Kabel Yang Digunakan :}

Jumlah inti dan luas penampang : $2 \times 1.5 \mathrm{~mm}$

Jumlah kawat dalam satu inti

: 1 buah

Diameter inti kabel

: $1.38 \mathrm{~mm}$

Isolasi nominal $\mathrm{S} 1$

$: 0.7 \mathrm{~mm}$

Lapisan pembungkus inti S2

: $0.4 \mathrm{~mm}$

Selubung nominal S3

$: 1.2 \mathrm{~mm}$

Diameter luar

: $10 \mathrm{~mm}$

Panjang kabel yang di ukur

$: 1 \mathrm{~m}$

Data hasil Pengukuran kabel NYM $2 \times 1.5$ mm$^{2}$

Tabel 1. Hasil Pengukuran Arus Pada Kabel NYM 2 x 1.5 mm

\begin{tabular}{|c|c|c|c|c|c|c|c|}
\hline \multirow[t]{2}{*}{ No } & \multirow{2}{*}{$\begin{array}{c}\mathrm{V}(\mathrm{AC}) \\
\text { Volt }\end{array}$} & \multicolumn{6}{|c|}{ I (AC) Ampere } \\
\hline & & Tanpa tekukan & $\begin{array}{c}1 \mathrm{x} \\
\text { tekukan }\end{array}$ & $\begin{array}{c}2 \mathrm{x} \\
\text { tekukan }\end{array}$ & $\begin{array}{c}3 x \\
\text { tekukan }\end{array}$ & $\begin{array}{c}4 x \\
\text { tekukan }\end{array}$ & $\begin{array}{c}5 x \\
\text { tekukan }\end{array}$ \\
\hline 1 & 1 & 1.1 & 1.7 & 1.4 & 1.8 & 1.5 & 1.7 \\
\hline 2 & 1 & 1.1 & 1.7 & 1.4 & 1.8 & 1.4 & 1.8 \\
\hline 3 & 1 & 1.1 & 1.6 & 1.4 & 1.8 & 1.4 & 1.8 \\
\hline 4 & 1 & 1.1 & 1.6 & 1.5 & 1.8 & 1.4 & 1.8 \\
\hline 5 & 1 & 1.1 & 1.6 & 1.4 & 1.8 & 1.4 & 1.8 \\
\hline \multicolumn{2}{|c|}{ Rata-rata (A) } & 1.1 & 1.64 & 1.42 & 1.8 & 1.42 & 1.78 \\
\hline
\end{tabular}

Hasil Perhitungan Pengujian Kabel NYM 2 × 1.5 mm$^{2}$

Tabel 2. Data Hasil Perhitungan pengujian kabel NYM 2 x $1.5 \mathrm{~mm}$

\begin{tabular}{|c|l|c|c|c|c|c|}
\hline No & \multicolumn{1}{|c|}{ Jumlah tekukan } & $\begin{array}{c}\text { Vac } \\
(\text { Volt })\end{array}$ & $\begin{array}{c}\text { Iac rata-rata } \\
(\text { Ampere })\end{array}$ & $\begin{array}{c}\text { Rac/m } \\
(\mathrm{Ohm} / \mathrm{m})\end{array}$ & $\begin{array}{c}\text { Rac/km } \\
(\mathrm{Ohm} / \mathrm{km})\end{array}$ & $\begin{array}{c}\Delta \mathrm{P} \\
(\mathrm{Watt})\end{array}$ \\
\hline 1 & Tanpa tekukan & 1 & 1.1 & 0.9 & 900 & 1.08 \\
\hline 2 & Tekukan pertama & 1 & 1.64 & 0.6 & 600 & 1.61 \\
\hline 3 & Tekukan kedua & 1 & 1.42 & 0.7 & 700 & 1.41 \\
\hline 4 & Tekukan ketiga & 1 & 1.8 & 0.55 & 550 & 1.78 \\
\hline 5 & Tekukan keempat & 1 & 1.42 & 0.7 & 700 & 1.41 \\
\hline 6 & Tekukan kelima & 1 & 1.78 & 0.56 & 560 & 1.77 \\
\hline
\end{tabular}




\section{Grafik Data Hasil Perhitungan rugi daya pengujian tahanan kabel NYM 2 x $1.5 \mathrm{~mm}^{2}$}

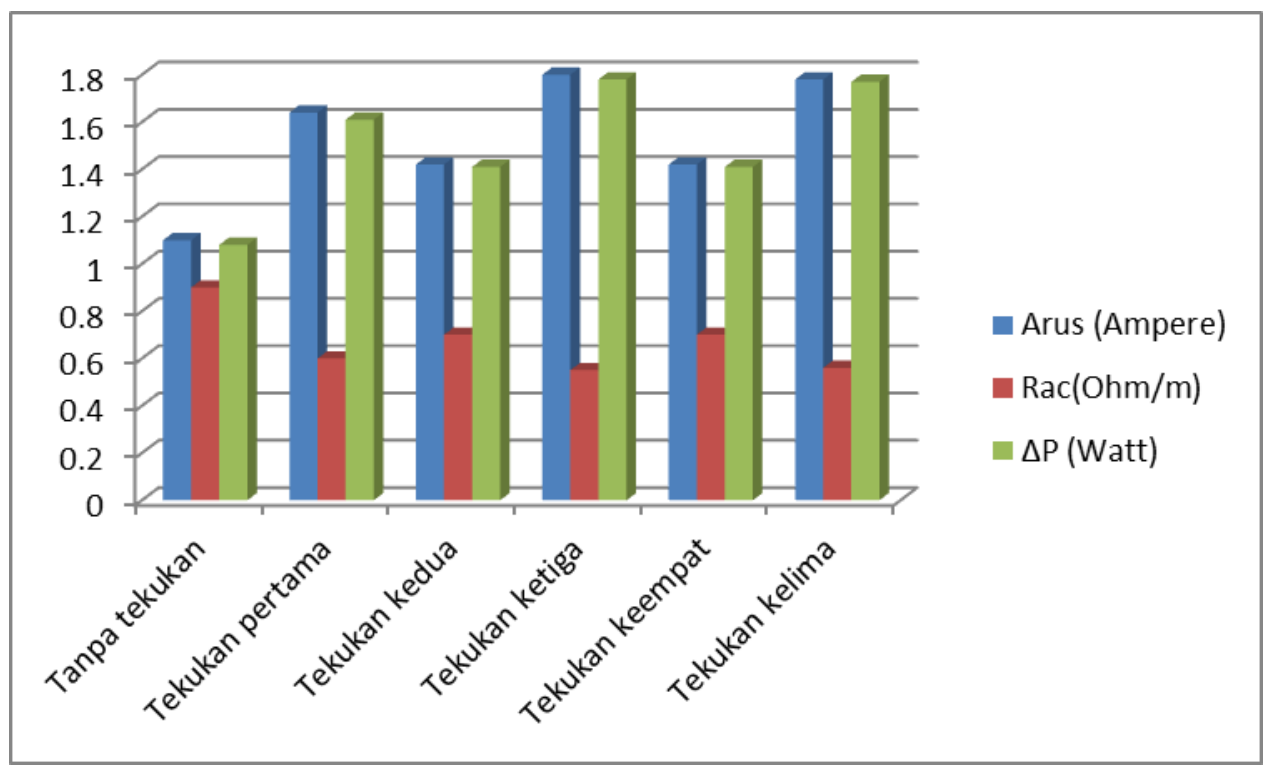

Gambar 4. Grafik Data Hasil Perhitungan rugi daya pengujian tahanan kabel NYM 2 x $1.5 \mathrm{~m}^{2}$

\section{Analisa hasil pengukuran dan perhitungan kabel NYM}

Dari nilai rata-rata hasil pengukuran didapat bahwa nilai arus setelah kabel ditekuk mengalami kenaikan. Pada penekuan pertama, nilai arus 1.1 Ampere naik menjadi 1.64 Ampere. Untuk penekukan yang kedua sampai kelima pada umumnya arus nya cenderung naik. Namun kenaikan tersebut tidak konstan, pada penekukan kedua dan keempat, nilai arusnya cenderung turun. Hal ini disebabkan arah tekukan yang tidak selalu searah. Dari hasil pengukuran arus tersebut, didapat nilai tahanan. Nilai tahanan akan semakin kecil jika kabel tersebut ditekuk. Nilai terendah dari tahanan kebel NYM yang diuji terdapat pada kabel yang ditekuk 3 kali yaitu $0.55 \Omega / \mathrm{m}(550 \Omega / \mathrm{km})$, dan nilai tahanan kabel NYM yang tertinggi adalah pada kabel yang tidak ditekuk yaitu $0.9 \Omega / \mathrm{m}(900 \Omega / \mathrm{km})$.

\section{KESIMPULAN}

Dari hasil analisa dapat diambil kesimpulan :

1. Hasil pengujian terhadap kabel yang tanpa ditekuk dan kabel yang ditekuk terlihat jelas perubahan nilai arusnya, yang semakin membesar karena kabel tersebut ditekuk

2. Perubahan nilai arus tersebut disebabkan karena perubahan nilai tahanan yang menurun karena adanya penekukan.

3. Terjadinya perubahan nilai arus yang naik turun dikarenakan arah dari tekukan pertama sampai ke tekukan kelima tidak selalu searah. 


\section{DAFTAR PUSTAKA}

[1] Rukdas Imam Faizal, "Analisis Temperatur Kabel Terhadap Penekukan dan Besar Arus", Universitas Indonesia, 2009

[2] Joko Priyono dkk, "Analisa Pengaruh Penekukan Dan Besarnya Arus Pada Saluran Distribusi Dan Instalasi Yang Berpengaruh Terhadap Peningkatan Temperatur Dan Penurunan Daya Isolasi Kabel Di PT. Dana Purna Investama (BCA KCU Diponegoro Surabaya)", UM Surabaya

[3] Alfith, S.Pd, M.Pd, "Kelayakan Instalasi Listrik Rumah Tangga Dengan Pemakaian Lebih Dari 10 Tahun Di Kanagarian Nanggalo Kecamatan Koto XI Tarusan Kabupaten Pesisir Selatan", Institut Teknologi Padang

[4] http://staff.uny.ac.id/sites/default/files/pendidikan/dr-djoko-laras-budiyo-taruno/materiinstalasi-listrik.pdf

[5] https://skemaku.com/mari-mengenal-jenis-jenis-kabel-listrik-beserta-kegunaannya/

[6] https://sbaskoro.wordpress.com/2008/01/28/tipe-kabel-untuk-instalasi-rumah/ 